\title{
The effect of a token economy system program and physical activity on improving quality of life of patients with schizophrenia: a pilot study
}

\author{
Dimitrios Kokaridas $^{1}$, Georgia Maggouritsa ${ }^{1}$, Periklis Stoforos ${ }^{2}$, Asterios Patsiaouras ${ }^{1}$, \\ Yiannis Theodorakis ${ }^{1}$, Nikolaos Diggelidis ${ }^{1}$
}

${ }^{1}$ University of Thessaly, Department of Physical Education and Sport Science, Trikala, Greece

${ }^{2}$ Psychiatrist, Director of Psychiatry Unit, Trikala, Greece

\section{Email address:}

dkokar@pe.uth.gr (D. Kokaridas),gmag@pe.uth.gr (G. Maggouritsa), pstoforos@yahoo.gr (P. Stoforos), spats@pe.uth.gr (A. Patsiaouras), theodorakis@pe.uth.gr (Y. Theodorakis), nikdig@pe.uth.gr (N. Diggelidis)

To cite this article:

Dimitrios Kokaridas, Georgia Maggouritsa, Periklis Stoforos, Asterios Patsiaouras, Yiannis Theodorakis, Nikolaos Diggelidis. The Effect of a Token Economy System Program and Physical Activity on Improving Quality of Life of Patients with Schizophrenia: A Pilot Study. American Journal of Applied Psychology. Vol. 2, No. 6, 2013, pp. 80-88. doi: 10.11648/j.ajap.20130206.13

\begin{abstract}
The aim of this pilot study was to examine the effect of an exercise and token economy system program on improving quality of life of patients with schizophrenia. Thirty (30) patients with schizophrenia separated in three groups (control group, an exercise observation with tokens group and an actual exercise with tokens group) of 10 individuals, took part in an eight weeks exercise program combining physical activity with token economy behavioral treatment. Data included the use of SF-36 Quality of Life Questionnaire (QLQ). Experiment group B participants as compared to those of the experiment group A and control group individuals found at the end of the exercise program as experiencing less problems with daily activities and felling more energetic and vigorous leading to an improved mental component score. Overall, findings are encouraging concerning the effect of a combined exercise and token economy program on improving quality of life of patients with schizophrenia.
\end{abstract}

Keywords: Exercise, Behavioral Therapy, Psychological Parameters, Schizophrenia

\section{Introduction}

Schizophrenia is typically viewed as a chronic severe psychotic disorder characterized by delusions, incoherence and physical agitation and marked by disorganized speech, thinking emotions and behaviors that lead to a poor long-term outcome [1]. As a disorder, schizophrenia causes significant social or occupational dysfunction, deterioration in social, occupational and interpersonal relationships [2], cognitive impairment [3], poor physical health and higher risk of medical illnesses' occurrence [4]. Furthermore, schizophrenia leads to the adoption of inappropriate health habits such as excessive smoking, drinking, poor nutrition [5] and lack of physical exercise that further reduces functional exercise capacity [6]. In fact, physical inactivity is one of the most prevalent risk factors for the development of obesity, diabetes and cardiovascular disease $[7,8]$, whereas the most effective antipsychotic drugs recognized for their treatment advantages are associated with negative side effects such as weight gain and diabetes and poor quality of life [9].

Since not only medication therapy itself can be sufficient [10], exercise interventions as an adjunct therapy for psychosis have often been proposed [11, 12], with researches showing the links of physical exercise with improvement of physical health parameters [13, 14], reductions in depression and anxiety $[15,16]$, and an increased social interaction and psychological well-being $[17,18,19]$.

Regular physical exercise can be a useful nonpharmacological application to improve mental state and quality of life of patients with schizophrenia, proven to be more cost effective method in comparison to other common treatments such as medication and psychological therapies $[1,12]$. Quite clearly, research supporting the links between physical activity and health of individuals with schizophrenia points out that physical activity should be incorporated into clinical practice [20].

Nevertheless, the systematic study of physical activity in 
this population has only begun [21]. Although it has long been established that patients with schizophrenia seldom exercise and are less physically active mainly due to apathy and lack of motivation [22], few studies have tried to promote exercise behavior since drop-out rates from exercise are significantly higher compared to general population [23].

Increase of positive exercise behavior to improve health is a key issue and since drop out is mostly related to personality characteristics and subjective mood states [24], physical activity interventions should incorporate not only application of exercises but also implementation of behavior strategies [25]. In a study, researchers incorporated exercise as well as behavioral interventions showing that such interventions can increase exercise behavior [26], whereas in reference [22], researchers in their motivational intervention achieved higher attendance rates than previous study.

Apart from these two studies, no other research efforts have been noted to combine exercise set within a behavioral modification program that is necessary to produce desirable results [27]. Researches incorporating behavioral interventions in settings other than exercise used a token economy system approach that has been proved to be an effective behavioral treatment for schizophrenia patients [28, $29]$, that reduces the severity of persistent symptoms [30, 31].

A token economy (TE) is a type of effective behavioral therapy which sets target behaviors related with the improvement of individual's attendance in daily activities, specifies direct rewards (tokens) and provides these rewards at pre-determined times as exchange units administered to the individual as soon as he/she expresses the desirable types of positive adaptive behavior [32, 33, 34]. Due to its effectiveness, token therapy in mental health rehabilitation programs for patients with psychosis is recommended [35].

However, reviewing the literature it seems that no studies are conducted combining physical activity with token economy behavioral treatment. Thus, the purpose of the study was to examine the effect of an exercise and token economy system program on improving quality of life of patients with schizophrenia and promoting exercise behavior so as to minimize drop out risk.

\section{Main Body}

\subsection{Participants}

The sample consisted of 30 patients (38-61 years old, 20 men, 10 women) with schizophrenia, selected randomly by drawing lots from a total population of 45 residents receiving care for the last two years at a private psychiatry hospital, without prior participation in physical activity whatsoever. Following, the sample was randomly assigned in two groups (control and experiment). Control group participants $(n=10)$ agreed to sign the consent form so as to complete SF-36 QLQ prior and after the application of the training program, but did not attend any training session.

Next, a therapeutic alliance process including three 60 min. preparatory meetings was arranged prior program initiation between the psychiatrist and the researcher with all 20 patients remained. Therapeutic alliance process is of particular concern in the treatment of schizophrenia and its effect has been linked with positive psychological outcomes and performance in rehabilitation [36, 37, 38].

The great importance of health, its relation with physical activity and the effect of exercise on improving quality of life were discussed during the first meeting. Next meeting involved the building of trust, appreciation and collaborative relationship of patients toward the researcher so as to minimize dropout risk. Since patients already had an established relationship with the psychiatrist, meetings served as a therapeutic bond and agreement on the goals and tasks of therapy [39] between the participants and the researcher with the use of Working Alliance Inventory [40].

In particular, the psychiatrist with the researcher being present developed an open conversation with patients, using item 2 "My therapist and I both feel confident about the usefulness of our activity" related to agreement about the tasks of the program, items 1 "My therapist and I agree about the steps to be taken", 8 "We agree on what is important to work on", 17 "I believe that my therapist shows genuine interest for my own good" and 23 "I feel that my therapist appreciates me" concerning the building of bond between the patients and the researcher and items 14 "goals of these meetings are important for me" and 30 "My therapist and I cooperate to set common therapy goals" as regards to mutual agreement about program goals. During the last meeting, information was provided concerning the content of the exercise program and participants were randomly separated in two groups of 10 patients, an exercise observation with tokens group (experiment group A) and an actual exercise with tokens group (experiment group B) for the observers and participants of the program respectively.

The study was approved by the Institutional Review Board and informed consent was received from all participants prior program initiation. A written medical clearance for exercise was also provided for each participant.

\subsection{Training Program}

The duration of the training program was 8 weeks at a frequency of three training sessions per week, of 45 minutes each session. Control group individuals, did not observe or participate in any training session. As to experiment group A participants, their task was not to participate but solely to observe the training program of the experiment group B, receiving the same rewards (tokens) in each training session as a reward of their consistency. Since our study focused exclusively on the psychological effects of exercise and not physical ones, our intention was to examine whether observing the training program could lead to positive psychological outcomes of experiment group A participants.

Each training session for the experiment group B 
participants included a 5 minutes warm-up period of breathing and flexibility exercises followed by 10 minutes of walking, 25 minutes of aerobic, strength, balance and co-ordination exercises and a cool-down period of 10 minutes of breathing and relaxation exercises. Stretching exercises were included prior walking to improve flexibility, reduce muscular soreness and minimize injury [22], whereas walking was included as the easiest, safest, and most readily available physical activity that channels tension tendency for restlessness and wandering into a beneficial activity [21]. All participants of the experiment group B were reminded prior each training session about the importance of starting slowly and gradually increasing walking pace up to a level self-perceived as intense, plus warming up and cooling down the muscles by stretching. Aerobic exercises were incorporated in the program since they significantly reduce depression and anxiety in people with schizophrenia [41, 42].

Breathing and relaxation exercises were similarly included for stress management purposes [43]. Abdominal exercises and modified push ups were included to build weak muscle strength [44]. Balance and co-ordination activities were used to improve stability deficits that often constitute a barrier to perform motor activities [45]. Apart from walking, all activities were different in each training session in an attempt to keep the interest of patients with schizophrenia and provide variability.

Overall, the purpose was to provide a training program that fairly covers all aspects that constitute the general physical condition of each individual and takes moderate physical effort to perform, as perceived by participants. Studies showed that mild to moderate aerobic exercise is an effective programme for decreasing psychiatric symptoms and for increasing QOL in patients with schizophrenia [1, 13, 18]. Moderate intensity of training was described as a target to experiment group B participants prior program initiation, as the physical effort that makes them breathe somewhat harder than normal [46].

A formal sheet of goal achievement used solely to record token attainment, was held for each patient of the experiment group B in each training session (see Table 1).

Table 1. Formal Sheet of Goal Achievement

\begin{tabular}{|c|c|c|c|c|c|c|c|}
\hline \multirow[b]{3}{*}{ Weeks } & \multicolumn{7}{|c|}{ Goals } \\
\hline & \multicolumn{5}{|c|}{ Participation } & \multicolumn{2}{|c|}{ Number of tokens } \\
\hline & $\begin{array}{l}\text { Training } \\
\text { sessions }\end{array}$ & $\begin{array}{c}\text { Sessions per } \\
\text { week }\end{array}$ & $\begin{array}{c}\text { Time (min) of intense } \\
\text { walking }\end{array}$ & $\begin{array}{l}\text { Total time }(\mathrm{min}) \text { per } \\
\text { training session }\end{array}$ & $\begin{array}{c}\text { Total time (min) } \\
\text { per week }\end{array}$ & $\begin{array}{c}\text { per training } \\
\text { session }\end{array}$ & per week \\
\hline \multirow{3}{*}{$1 \mathrm{st}$} & $1 \mathrm{a}$ & & & & & & \\
\hline & $1 b$ & & & & & & \\
\hline & $1 \mathrm{c}$ & & & & & & \\
\hline \multirow{3}{*}{ 2nd } & $2 a$ & & & & & & \\
\hline & $2 b$ & & & & & & \\
\hline & $2 \mathrm{c}$ & & & & & & \\
\hline \multirow{3}{*}{3 th } & $\mathrm{a}$ & & & & & & \\
\hline & $\mathrm{b}$ & & & & & & \\
\hline & c & & & & & & \\
\hline
\end{tabular}

The same formal sheet was also held for experiment group A participants, recording only the number of tokens received per session.

Recording of the goal achievement sheet for each participant was kept by the researcher and a second observer who was also present to monitor recording procedure and results. At the end of each training session, the researcher and the second observer had a meeting so as to discuss each patient's performance according to the format sheet. Inter-observer agreement was calculated by dividing the lowest number of agreements by the highest number of agreements for each task described in each column of the formal sheet. Inter-observer examination demonstrated that the researchers were in $100 \%$ agreement throughout the study, with an inter-observer reliability of at least $80 \%$ considered as acceptable [47].

\subsection{Application of the Token Economy System}

In each training session, each participant of the exercise observation with tokens group (experiment group A) and the actual exercise with tokens group (experiment group B) had the opportunity to receive two tokens referred to as 'credit', that is, prior the beginning one token (a plastic coin) was awarded for being on time and at the end of the training session the second token (participation certificate) rewarded the consistency of patients to observe (experiment group A) or participate (experiment group B) the whole 45 minutes session required. All individuals were allowed to keep their tokens after training.

Following three sessions, only the individuals who gained 6 tokens had the right to receive a more significant (bigger) token as a bonus of their consistency and appropriate behavior. Number of smaller and bigger tokens provided throughout the program to both experiment groups was gradually reduced without however being completely 
withdrawn (Table 2). Tokens could not be exchanged for other goods or cash neither participants could purchase items with them.

Table 2. Token Economy Schedule

\begin{tabular}{|c|c|c|c|c|c|}
\hline \multirow[b]{2}{*}{ Weeks } & \multirow[b]{2}{*}{$\begin{array}{l}\text { Training } \\
\text { Sessions }\end{array}$} & \multicolumn{3}{|c|}{ Number of smaller tokens } & \multirow[b]{2}{*}{$\begin{array}{l}\text { Bigger } \\
\text { tokens }\end{array}$} \\
\hline & & $\begin{array}{l}\text { 1st } \\
\text { session }\end{array}$ & $\begin{array}{l}\text { 2nd } \\
\text { session }\end{array}$ & $\begin{array}{l}\text { 3rd } \\
\text { session }\end{array}$ & \\
\hline $1 \mathrm{st}$ & $1,2,3$ & 2 & 2 & 2 & T- shirt \\
\hline 2nd & $4,5,6$ & 2 & 2 & 2 & Hat \\
\hline 3 rd & $7,8,9$ & 2 & 2 & 2 & Cup \\
\hline 4 th & $10,11,12$ & 2 & 2 & 2 & \\
\hline 5 th & $13,14,15$ & 2 & 2 & 2 & Hand bag \\
\hline 6th & $16,17,18$ & 1 & 1 & 1 & \\
\hline 7 th & $19,20,21$ & 1 & 1 & 1 & Medal \\
\hline 8th & $22,23,24$ & 1 & 1 & 1 & Trophy \\
\hline
\end{tabular}

As shown in Table 2, during the first three weeks in each one of the training sessions both smaller tokens (prior and after training) were provided, whereas the bigger token was also provided at the end of each week. The 4 th week patients received their two tokens in each session but at the end of the week no bigger token was provided. In other words, the bigger token from the $4^{\text {th }}$ to the $7^{\text {th }}$ was provided every two weeks and not every week as previously, that is, there was a reduce in frequency. In addition, during the last 3 weeks, the first small token (plastic coin) was also removed, that is, there was a reduction in number of smaller tokens provided, in an attempt to ascertain whether individuals of both experiment groups adopted the desirable behavior to be on time for training not due to the reward given but due to their eagerness to observe (experiment group 1) or participate (experiment group 2) in the training sessions.

\subsection{Instruments}

The instrument selected and administered prior and after the exercise program as a face to face interview by the researcher and a second observer to all participants of three groups, was the SF-36 quality of life questionnaire [48], found to exhibit good reliability and validity concerning people with schizophrenia [49], and also used in the very recent study examining the relation between lack of physical activity and quality of life of patients with schizophrenia [6]. The SF-36 is designed to examine individual's perceptions regarding quality of life in relation to eight different items of functioning, that is, physical functioning, role limitations due to physical problems, bodily pain, general health, social functioning, energy/vitality, role limitations due to emotional problems and mental health. The first four domains are summarized into a physical component score, whereas the later four domains constitute a mental component score. Scores range from 0 to 100 , with higher scores indicating a better health related quality of life.

\subsection{Statistical Analysis}

Statistical analysis included the use of Statistical Package of Social Sciences (SPSS 17.0). Cronbach's $\alpha$ reliability analysis was included to examine internal consistency of instrument's variables. Kolmogorov - Smirnov analysis was used to examine normality of sample distribution. The null distribution of this statistic K-S test is calculated under the null hypothesis that the samples are drawn from the same distribution (in the two-sample case). Since sample distribution according to Kolmogorov - Smirnov analysis was normal, planning application included a $2 \times 3$ measurement (pre- post-test) x Group (control group, experiment group A, experiment group B) with repeated measurements (ANOVA repeated measures) used to locate possible differences existing among the treatment in terms of SF36 variables. Another alternative procedure is using the multivariate test statistics (MANOVA) since they do not require the assumption of sphericity. However, this procedure can be less powerful than using repeated measures ANOVA, especially when sphericity violation is not large or sample sizes are small. Researchers suggested that when you have a large violation of sphericity and your sample size is greater than $k+10$, then a MANOVA is more powerful [50]; in other cases, repeated measures design should be selected. ANOVA results were based on Greenhouse-Geisser test. The importance of differences between the means of cells was examined with the application post hoc test of multiple comparisons Bonferroni. Level of statistical significance was set at $\mathrm{p}<0.05$.

\subsection{Results}

Test distribution according to Kolmogorov - Smirnov analysis was normal, since no significant results for all variables according to K-S Z test were noticed. Cronbach's a reliability analysis revealed an internal consistency ranging from acceptable $(\mathrm{a}=.676)$ to high $(\mathrm{a}=.931)$ for social functioning and role physical respectively (see Table 3 ).

Table 3. Sample distribution and reliability analysis

\begin{tabular}{lcccc}
\hline \multirow{1}{*}{\multicolumn{1}{c}{ Variables }} & \multicolumn{2}{c}{ Kolmogorov-Smirnov } & \multicolumn{2}{c}{ Cronbach's $\boldsymbol{\alpha}$} \\
& pre-test & post-test & pre-test & post-test \\
\hline role physical & .629 & .967 & .720 & .931 \\
physical function & .629 & 1.088 & .909 & .891 \\
bodily pain & 1.257 & .725 & .901 & .888 \\
general health & .556 & .967 & .783 & .850 \\
vitality & .871 & 1.209 & .775 & .897 \\
social function & .339 & .532 & .676 & .700 \\
role emotional & .411 & 1.209 & .887 & .926 \\
mental health & .846 & .846 & .795 & .826 \\
physical component & .629 & .653 & .775 & .895 \\
score & & & & \\
mental component & .822 & 1.209 & .895 & .875 \\
score & & & & \\
\hline
\end{tabular}

Interaction of factors (variable and groups) showed no statistically significant pre-test results in physical functioning ( $\mathrm{F} 2,27=.145, \mathrm{p}=.87, \eta 2=.011, \mathrm{P}=.070)$, bodily pain $(\mathrm{F} 2,27=3.11, \mathrm{p}=.61, \eta 2=.187, \mathrm{P}=.550)$, general health 
(F2,27=1.538, $\mathrm{p}=.23, \eta 2=.102, \mathrm{P}=.298)$, social-function (F2,27=2.314, $\mathrm{p}=.12, \eta 2=.146, \mathrm{P}=.428)$, mental health $(\mathrm{F} 2,27=.155, \quad \mathrm{p}=.86, \quad \eta 2=.011, \quad \mathrm{P}=.072)$ and physical component $(\mathrm{F} 2,27=1.268, \mathrm{p}=.30, \eta 2=.086, \mathrm{P}=.252)$. No statistical significant differences were also noticed between the groups in physical function $(\mathrm{F} 2,27=.187, \mathrm{p}=.83, \eta 2$ $=.014, \mathrm{P}=.076)$, bodily pain $(\mathrm{F} 2,27=3.36, \mathrm{p}=.051, \eta 2=.199$, $\mathrm{P}=585)$, general health $(\mathrm{F} 2,27=1.307, \mathrm{p}=.29, \eta 2=.088$, $\mathrm{P}=258)$, social function $(\mathrm{F} 2,27=1.322, \mathrm{p}=.28, \eta 2=.089$, $\mathrm{P}=261)$, mental health $(\mathrm{F} 2,27=2.235, \mathrm{p}=.13, \eta 2=.142$, $\mathrm{P}=.415)$, and physical component $(\mathrm{F} 2,27=.648, \mathrm{p}=.53, \eta 2$ $=.046, \mathrm{P}=.147)$.

Furthermore, interaction of factors (time and groups) showed statistically significant results in favor of post measurements in the following SF-36 factors: a) role physical $(\mathrm{F} 2,27=5.529, \mathrm{p}=.010, \eta 2=.291, \mathrm{P}=.810)$, with statistically significant main effect within groups (F1,27=8.102, $\mathrm{p}=.008, \eta 2=.231, \mathrm{P}=.783$ ) and Bonferroni correction revealing statistically significant differences between experiment group $\mathrm{B}$ and control group ( $\mathrm{I}-\mathrm{J}=4.00$, $\mathrm{SD}=1.757, \mathrm{p}=.046)$ and between experiment group $\mathrm{B}$ and $\mathrm{A}$ (I-J=4.00, $\mathrm{SD}=1.757, \mathrm{p}=.046) . \quad \mathrm{b})$ energy/vitality (F2,
$27=1.114, \mathrm{p}=.050, \eta 2=.076, \mathrm{P}=.225)$, with no statistically significant main effect within groups $(\mathrm{F} 1,27=.421, \mathrm{p}=.52$, $\eta 2=.015, \mathrm{P}=.096)$ and Bonferroni correction revealing statistically significant differences between experiment group $\mathrm{A}$ and $\mathrm{B}(\mathrm{I}-\mathrm{J}=3.60, \mathrm{SD}=1.418, \mathrm{p}=.036)$. c) role emotional ( $\mathrm{F} 2,27=4.188, \mathrm{p}=.026, \eta 2=.237, \mathrm{P}=687)$, with statistically significant main effect within groups $(\mathrm{F} 1,27=7.667, \mathrm{p}=.010, \eta 2=.221, \mathrm{P}=.761)$ and Bonferroni correction revealing statistical significant differences between experiment group $\mathrm{A}$ and $\mathrm{B}(\mathrm{I}-\mathrm{J}=3.30, \mathrm{SD}=1.334$, $\mathrm{p}=.030)$, and between experiment group $\mathrm{B}$ and control group (I-J=3.60, SD=1.583, p=.046). d) mental component (not statistical significant interaction $\mathrm{F} 2,27=2.324, \mathrm{p}=.117$, $\eta 2=.147, \mathrm{P}=.430)$ with statistically significant main effect within groups $(\mathrm{F} 1,27=4.082, \mathrm{p}=.050, \eta 2=.131, \mathrm{P}=.495)$ and Bonferroni correction revealing statistically significant post-test differences between experiment group A and B ( $\mathrm{I}-\mathrm{J}=9.00, \mathrm{SD}=3.312, \mathrm{p}=.034)$, and between experiment group $\mathrm{B}$ and control group $(\mathrm{I}-\mathrm{J}=6.70, \mathrm{SD}=3.312, \mathrm{p}=.049)$ (Tables 4 \& 5).

Table 4. Arithmetic means, standard deviations and Bonferroni 's post hoc tests for statistically significant results

\begin{tabular}{|c|c|c|c|c|c|c|}
\hline \multirow{2}{*}{ Variables } & \multirow{2}{*}{ Groups } & \multicolumn{2}{|c|}{ 1. pre-test } & \multicolumn{2}{|c|}{ 2. post-test } & \multirow{2}{*}{ Post hoc test (Bonferroni)* } \\
\hline & & M & SD & M & SD & \\
\hline \multirow[t]{3}{*}{ role physical } & a. Experiment group A & 13.40 & 3.27 & 14.80 & 4.94 & \multirow{3}{*}{$\begin{array}{l}2 a-2 b(p=.046) \\
2 b-2 c(p=.046)\end{array}$} \\
\hline & b. Experiment group B & 13.50 & 4.93 & 18.80 & 1.62 & \\
\hline & c. Control Group & 15.30 & 4.88 & 14.80 & 4.39 & \\
\hline \multirow[t]{3}{*}{ vitality } & a. Experiment group A & 12.70 & 2.75 & 12.40 & 4.25 & \multirow{3}{*}{$2 \mathrm{a}-2 \mathrm{~b}(\mathrm{p}=.036)$} \\
\hline & b. Experiment group B & 14.30 & 4.27 & 16.00 & 2.11 & \\
\hline & c. Control Group & 13.10 & 2.73 & 12.90 & 2.77 & \\
\hline \multirow[t]{3}{*}{ role emotional } & a. Experiment group A & 9.50 & 3.38 & 10.90 & 3.90 & \multirow{3}{*}{$\begin{array}{l}2 a-2 b(p=.030) \\
2 b-2 c(p=.046)\end{array}$} \\
\hline & b. Experiment group B & 10.10 & 3.90 & 14.20 & 1.14 & \\
\hline & c. Control Group & 13.10 & 3.32 & 12.80 & 3.19 & \\
\hline \multirow[t]{3}{*}{ mental component } & a. Experiment group A & 47.70 & 8.15 & 50.40 & 11.10 & \multirow{3}{*}{$\begin{array}{l}2 \mathrm{a}-2 \mathrm{~b}(\mathrm{p}=.034) \\
2 \mathrm{~b}-2 \mathrm{c}(\mathrm{p}=.049)\end{array}$} \\
\hline & b. Experiment group B & 51.70 & 8.78 & 59.40 & 3.81 & \\
\hline & c. Control Group & 53.40 & 4.72 & 52.70 & 5.19 & \\
\hline
\end{tabular}

* pairs of groups between whom significant differences have been detected

Table 5. Repeated ANOVA of SF 36 variables with statistically significant results**

\begin{tabular}{|c|c|c|c|c|c|c|}
\hline Variables & & Sum of Square & df & Mean Square & $\mathbf{F}$ & $\mathbf{p}$ \\
\hline \multirow[t]{4}{*}{ Role physical } & Between groups & 21.050 & 2 & 10.525 & .776 & .47 \\
\hline & Within subjects & 64.067 & 1 & 64.067 & 8.102 & .008 \\
\hline & Interaction & 87.433 & 27 & 43.717 & 5.529 & .010 \\
\hline & Total & 172.550 & 30 & & & \\
\hline \multirow[t]{4}{*}{ Vitality } & Between groups & 77.233 & 2 & 38.617 & .101 & .049 \\
\hline & Within subjects & 2.400 & 1 & 2.400 & .421 & .52 \\
\hline & Interaction & 12.700 & 27 & 6.350 & 1.114 & .050 \\
\hline & Total & 92.333 & 30 & & & \\
\hline \multirow[t]{4}{*}{ Role emotional } & Between groups & 80.033 & 2 & 40.017 & 2.574 & .095 \\
\hline & Within subjects & 45.067 & 1 & 45.067 & 7.667 & .010 \\
\hline & Interaction & 49.233 & 27 & 24.617 & 4.188 & .026 \\
\hline & Total & 174.333 & 30 & & & \\
\hline \multirow[t]{4}{*}{ Mental component } & Between groups & 430.00 & 2 & 215.00 & 2.998 & .053 \\
\hline & Within subjects & 156.817 & 1 & 156.817 & 4.082 & .050 \\
\hline & Interaction & 178.533 & 27 & 89.267 & 2.324 & .117 \\
\hline & Total & 765.350 & 30 & & & \\
\hline
\end{tabular}

**Note: Results based on Greenhouse-Geisser test. 


\subsection{Discussion}

The purpose of the study was to examine the effect of an exercise and token economy system program on improving quality of life of patients with schizophrenia as well as the promotion of positive behavior towards exercise so as to minimize drop out risk. The study focused on how exercise improves psychological well-being of persons with schizophrenia considering the subjective feelings of what motivates or interests each individual to take part in physical activity as a very important part of their treatment [51]. Benefits of physical activity on promoting physical health of patients with schizophrenia is already well documented [13], hence, exercise programs for persons with severe mental illness should use physical activity as a mean to help patients pursue other areas of their lives which they see as meaningful for general enjoyment [52]. Seeing physical activity as enjoyable in its own right [19], could help persons to adopt more healthy attitudes that will include physical activity as part of their everyday routine so as to promote their psychological well-being and quality of life.

Post results between the three groups showed the positive effect of the physical activity program on improving quality of life and psychological well- being parameters of experiment group B participants, in agreement with mental health/general psychological well-being benefits found in high-quality score studies [1, 18].

In particular, experiment group $\mathrm{B}$ participants as compared to those of the experiment group A and control group individuals reported at the end of the exercise program as experiencing less problems with daily activities or emotional difficulties and felling more energetic and vigorous leading to an improved mental component score referring to less psychological distress and social limitations. No differences were noted between the experiment group A individuals observing the training program with control group individuals who did not observe or participate in any training session.

Appreciating exercise means not only getting involved as a participant but also as a spectator, fan, or advocate so as to increase self-awareness and commitment toward exercise and promote belief that physical activity is a fun, enjoyable and satisfying experience and leisure process [53]. Thus, the experiment group A was included in the design of this study in an attempt to ascertain whether observation of a new and enjoyable experience such as physical activity that was not previously available in the everyday program of the psychiatry hospital, could influence positively the quality of life of observing residents receiving care for the last two years within psychiatric premises. Findings suggest that observation of the training program was not a factor that influenced positively the quality of life aspects for experiment group A individuals to the extent that could lead to statistically significant differences compared to control group individuals, although slightly improved scoring of SF-36 summary measures for experiment group A.
No drop-outs occurred during intervention. In our view, drop outs have not been occurred for the following reasons: a) First, the therapeutic alliance process that took place prior program initiation. The purpose of the three preparatory meetings was not to use WAI in a formal way. Since patients already had an established relationship with the psychiatrist, our intention was to use specific WAI tasks so as to build up a trust and collaborative relationship of patients with the researcher plus to casually develop an open conversation with patients regarding benefits of physical activity and their commitment to exercise. In this way, the therapeutic alliance process was used prior program initiation solely as a mean to minimize drop out risk.

b) The careful structure of the training program in terms of its moderate intensity, integration of activities that developed all aspects (strength, flexibility, balance and aerobic capacity) that constitute the general physical condition of each individual and the variability of exercises that apart from walking were completely different in each training session and kept participants 'on their toes'.

The focus of this study was not to provide temporary physiological benefits to persons with schizophrenia but to promote positive behavior of patients toward physical activity as a mean to improve their quality of life. In our view, the purpose of the study itself focusing only in psychological parameters without having to use any instruments to measure physiological outcomes was also a possible reason why not dropouts occurred.

c) The application of the token economy system. An important development in cognitive remediation of patients with schizophrenia is a focus on motivation. Despite statements that use of extrinsic reward is undesirable and much research demonstrates the important role of internal motivation in learning [54], almost none of this research has been done with psychiatric patients who are characterized by significant cognitive deficits, low levels of internal motivation and a very low spontaneous engagement in therapeutic behavior. There is a long history of research demonstrating that delivery of extrinsic rewards is associated with positive outcomes related to both behavioral and cognitive rehabilitation from early demonstrations of the positive effects of the token economy up through the present day [55]. Thus, extrinsic rewards have been typically used in highly supportive interpersonal environments for patients with schizophrenia so as to reduce inappropriate behaviors and increase appropriate ones, promote competence and autonomy and improve cognitive functioning and social learning [56, 57].

In our study, tangible rewards (tokens) were delivered in response to performance of specific target behaviors, for patients being on time, attending the whole training session and demonstrating such consistency and appropriate behavior throughout the exercise program. Initially, experiment group participants were more eager to receive their reward and it seemed that their behavior was mostly associated in expectation of gaining their tokens, as each 
time they all waited patiently in line to receive their reward and frequently asked questions if, when and what kind of tokens they were about to receive. As the program progressed individuals got familiarized with the reward procedure and questions gradually stopped.

At the end of the first week, receiving their first bigger token was quite impressive in the minds of all those who collected all smaller tokens. However, only 6 out of 10 experiment group B participants gained all 6 tokens and had the right to receive the more significant token as a bonus of their consistency. Four individuals did not receive their bigger token and they strongly protested about this issue, demanding to an extent to receive their gift. Behavior of the researcher was firm in every such occasion. No bigger tokens were given to non-consistent participants no matter how strong complaints were and an immediate explanation was always provided concerning the reason for not doing this, in an attempt to create a direct "cause and effect" relation. As a result, at the end of the 3rd week, all experiment group B participants earned the right to receive their bigger token.

The 4th week no end reward was provided according to token economy schedule. Participants looked quite puzzled about this but they haven't said anything openly to the researcher. Commencing the 5th week, the first smaller token was removed in an attempt to verify whether individuals of experiment groups were on time for training not due to the reward given but due to their desire to observe or exercise. The fact than no delays occurred prior each session during the last three weeks is considered a very positive finding of this study.

\section{Conclusions}

Overall, it seems that the application of the token economy system was useful in motivating individuals to participate. However, exploring extrinsic and intrinsic motivation of individuals with schizophrenia was not a purpose of our study to ascertain whether the use of extrinsic rewards is necessary to set the conditions under which internal motivation can develop [58]. Future studies should focus more on exploring the relationship between motivation and cognitive remediation in schizophrenia [55].

Nevertheless, results are encouraging concerning the effect of a combined exercise and token economy system program on improving quality of life of patients with schizophrenia plus improving behavior toward exercise. Surely, this study appears the first of its kind so it is limited by its exploratory nature. Future studies using larger samples, longer in duration physical activity programs and follow ups are needed to further explore whether combination of exercise and token economy procedures provide similar positive results to persons with schizophrenia.

Furthermore, although therapeutic alliance process was used solely prior program initiation as a mean to minimize drop out risk, its inclusion in this study represents a limitation on whether the content of the exercise and token treatment was exclusively responsible to promote quality of life. Thus, future studies are needed to further examine the exercise and token economy influence on quality of life of patients with schizophrenia without the inclusion of therapeutic alliance process.

It should also be said that another limitation emerged with the completion of the exercise program when participants asked whether this program will continue. At that point, immediate considerations were raised among researchers in relation to finance provision of continuously accessible reinforcers as well as the additional staff and intensive effort required to maintain this type of treatment program [59].

Does this outweigh any advantages of token application in physical activity programs? In our opinion, to minimize drop out risk and promote healthy behaviors, physical activity programs should not stand 'alone' solely with a mean to provide temporary physiological benefits to persons with schizophrenia. Rather, exercise programs should be considered as an integral part of the overall therapy process in clinical settings. What is probably more important for physical activity interventions referring to such populations is to incorporate behavior strategies and procedures such as the token economy application and therapeutic alliance process in order to improve exercise habits as well as patients' perceptions towards physical activity as a mean to improve their quality of life and psychological well-being.

\section{References}

[1] Acil, S. Dogan, and O. Dogan, "The effects of physical exercises to mental state and quality of life in patients with schizophrenia", Journal of Psychiatric and Mental Health Nursing, 15(10), 2008, pp. 808-815.

[2] Sibitz, A. Unger, A. Woppmann, T. Zidek, and M. Amering, "Stigma resistance in patients with schizophrenia", Schizophrenia bulletin, 37(2), 2011, pp. 316-323.

[3] M.M. Kurtz, and A. Tolman, (2011). "Neurocognition, insight into illness and subjective quality-of-life in schizophrenia: What is their relationship?", Schizophrenia Research, 127 (1), 2011, pp. 157-162.

[4] D.R. Jones, C. Macias, P.J. Barreira, W.H. Fisher, W.A. Hargreaves, and C.M. Harding, "Prevalence, severity, and co-occurrence of chronic physical health problems of persons with serious mental illness", Psychiatric Services, 55 (11), 2004, pp. 1250-1257.

[5] C. Roick, A. Fritz-Wieacker, H. Matschinger, D. Heider, J. Schindler, S. Riedel- Heller, and M.C. Angermeyer, "Health habits of patients with schizophrenia", Social Psychiatry and Psychiatric Epidemiology, 42, 2007, pp. 268-276.

[6] D. Vancampfort, M. Probst, T. Scheewe, K. Maurissen, K. Sweers, J. Knapen, and M. De Hert, "Lack of physical activity during leisure time contributes to an impaired health related quality of life in patients with schizophrenia", Schizophrenia Research, 129(2-3), 2011, pp. 122-127.

[7] L.A. Lindamer, C. McKibbin, and G.J. Norman, “Assessment of physical activity in middle-aged and older adults with 
schizophrenia", Schizophrenia Research, 104, 2008, pp. 294-301.

[8] G.J. Jerome, D.R. Young, A. Dalcin, J. Charleston, C. Anthony, J. Hayes, and G. Daumit, "Physical activity levels of persons with mental illness attending psychiatric rehabilitation programs", Schizophrenia Research, 108 (1-3), 2009, pp. 252-257.

[9] P.E. Bebbington, M. Angermeyer, J.M. Azorin, S. Marwaha, F. Marteau, and M. Toumi, "Side-effects of antipsychotic medication and health-related quality of life in schizophrenia", Acta Psychiatrica Scandinavica, 119 (438), 2009, pp. 22-28.

[10] S. Doğan, O. Doğan, H. Tel, F. Coker, O. Polatöz, and F.B. Doğan, "Psychosocial approaches in outpatients with schizophrenia", Psychiatric Rehabilitation Journal, 27, 2004, pp. 279-282.

[11] D. Crone, L. Heaney, and C. Owens, "Physical activity and mental health", In L. Dugdill, D. Crone, \& R. Murphy (Eds.), Physical activity and health promotion: Evidenced-based approaches to practice, 2009, pp.198 -212, London: Blackwell.

[12] N. Ellis, D. Crone, R. Davey, and S. Grogan, "Exercise interventions as an adjunct therapy for psychosis: A critical review", British Journal of Clinical Psychology, 2007, 46(1), pp. 95-111.

[13] L.H. Beebe, L. Tian, A. Goodwin, N. Morris, S. Swant- Allen, and J. Kuldau, "Effects of exercise on mental and physical health parameters of persons with schizophrenia", Issues in Mental Health Nursing, 26(6), 2005, pp. 661-676.

[14] M. Fogarty, and B. Happell, "Exploring the benefits of an exercise program for people with schizophrenia: A qualitative study", Issues in Mental Health Nursing, 26(3), 2005, pp. 341-351

[15] N. Schmitz, J. Kruse, and J. Kugler, "The association between physical exercises and health-related of life in subjects with mental disorders: results from a cross-sectional survey", Preventive Medicine, 39(6), 2004, pp. 1200-1207.

[16] J.A.J. Smits, A.C. Berry, D. Rosenfield, M.B. Powers, E Behar, and M.W. Otto, "Reducing anxiety sensitivity with exercise", Depression and Anxiety, 25(8), 2008, pp. 689-699.

[17] G. Faulkner, and S. Biddle, "Exercise as an adjunct treatment for schizophrenia: a review of the literature", Journal of Mental Health 8(5), 1999, pp. 441-457.

[18] G. Faulkner, and A. Sparkes, "Exercise as therapy for schizophrenia: An ethnographic study", Journal of Sport \& Exercise Psychology, 21, 1999, pp.52-69.

[19] J. Holley, D. Crone, P. Philip Tyson, and G. Lovell, "The effects of physical activity on psychological well-being for those with schizophrenia: A systematic review", British Journal of Clinical Psychology, 50, 2011, pp. 84-105.

[20] G. Faulkner, T. Cohn, and G. Remington, "Validation of a physical activity assessment tool for individuals with schizophrenia", Schizophrenia Research, 82(2), 2006, pp. 225-231.

[21] Richardson, G. Faulkner, J.McDevitt, G. Skrinar, D. Hutchinson, and J. Piette, "Integrating physical activity into mental health services for individuals with serious mental illness", Psychiatric Services, 56(3), 2005, pp. 324-331.

[22] L.H. Beebe, and K. Smith, "Feasibility of the Walk, Address, Learn and Cue (WALC) Intervention for Schizophrenia Spectrum Disorders", Archives of Psychiatric Nursing, 24 (1), 2010, pp. 54-62.

[23] S. Archie, J.H. Wilson, S. Osborne, H. Hobbs, and J. McNiven, "Pilot study: access to fitness facility and exercise levels in olanzapine-treated patients", Canadian Journal of Psychiatry, 48, 2003, pp. 628-632.

[24] S. Fassino, F. Amianto, G. Abbate Daga, and P. Leombruni, "Personality and psychopathology correlates of dropout in an outpatient psychiatric service", Panminerva Med., 49(1), 2007, pp. 7-15.

[25] D.R. Brown, "Physical activity, aging, and psychological well-being: An overview of the research", Canadian Journal of Sport Sciences, 17(3), 1992, pp. 185-193.

[26] M. Menza, B.Vreeland, S.Minsky, M.Gara, D.R.Radler, and M. Sakowitz, "Managing atypical antipsychotic-associated weight gain: 12-month data on a multimodal weight control program", Journal of Clinical Psychiatry, 65(4), 2004, pp. 471-477.

[27] G. Faulkner, A. Soundy, and K. Lloyd, "Schizophrenia and weight management: a systematic review of interventions to control weight", Acta Psychiatrica Scandinavica, 108(5), 2003, pp. 324-332.

[28] F. Dickerson, W.N. Tenhula, and L.D. Green-Paden, "The token economy for schizophrenia: review of the literature and recommendations for future research", Schizophrenia Research, 75(2-3), 2005, pp. 405-416.

[29] J.P. LePage, K. DelBen, S. Pollard, M. McGhee, L. VanHorn, J. Murphy, P. Lewis, A. Aboraya, and N. Mogg, "Reducing assaults on an acute psychiatric unit using a token economy: a 2-year follow-up", Behavioral Interventions, 18(3), 2003, pp. 179-190.

[30] R.P. Liberman, "The token economy”, American Journal of Psychiatry, 157(9), 2000, pp. 1398.

[31] Turkington, D. Kingdon, and P.J. Weiden, "Cognitive behavior therapy for schizophrenia", American Journal of Psychiatry, 163(3), 2006, pp. 365-373.

[32] L.B. Dixon, F. Dickerson, A.S.Bellack, M.Bennett, D.Dickinson, R.W.Goldberg, A. Lehman, N. Wendy, W.N. Tenhula, C. Calme, R.M. Pasillas, J. Peer, and J. Kreyenbuhl, " The 2009 Schizophrenia PORT Psychosocial Treatment Recommendations and Summary Statements", Schizophrenia Bulletin, 36 (1), 2010, pp. $48-70$.

[33] K. Zlomke, and L. Zlomke, "Token economy plus self-monitoring to reduce disruptive classroom behaviours", Behavior Analyst Today, 4(2), 2003, pp. 177-182.

[34] J.E. Comaty, M. Stasio, and C. Advokat, "Analysis of outcome variables of a token economy system in a state psychiatric hospital: a program evaluation", Research in Developmental Disabilities, 22(3), 2001, pp. 233-253.

[35] L. Mei-Feng, C. Jaw-Haw, C. Mei-Hsien, and H. Mei-Chi, "Significant experiences of token therapy from the perspective of psychotic patients", The Journal of Nursing Research, 14 (4), 2006, pp. 315-323. 
[36] L.W. Davis, and P.H. Lysaker, "Neurocognitive correlates of therapeutic alliance in schizophrenia", Journal of Nervous and Mental Disease, 192(7), 2004, pp. 508-510.

[37] C.M. Donnell, D.C. Lustig, and D.R. Strauser, "The working alliance: rehabilitation outcomes for persons with severe mental illness", Journal of Rehabilitation, 70(2), 2004, pp. 12-18.

[38] P.E. Smerud, and L.S. Rosenfarb, "The therapeutic alliance and family psychoeducation in the treatment of schizophrenia an exploratory prospective change process study", Journal of Consulting and Clinical Psychology, 76 (3), 2008, pp. $505-510$.

[39] E.S. Bordin, "The generalizability of the psychoanalytic concept of the working alliance", Psychotherapy: Theory, Research and Practice, 16(3), 1979, pp. $252-260$.

[40] A.O. Horvath, and L.S. Greenberg, "The development of the working alliance inventory". In L. Greenberg \& W. Pinsof (Eds.), Psychotherapeutic process: A research handbook, 1986, (pp.529-556), New York: Guilford Press.

[41] T.G. Plante, "Aerobic exercise in prevention and treatment of psychopathology," in Exercise psychology, P. Seraganian, Ed., 1993, pp.358-379, Wiley-Interscience, London.

[42] T. Pelham, and P. Campagna, "Benefits of exercise in psychiatric rehabilitation of persons with schizophrenia," Canadian Journal of Rehabilitation, 4, 1991, pp. 159-168.

[43] Starkey, H. Deleone, and R.B. Flannery, "Stress management for psychiatric patients in a state hospital setting, American Journal of Orthopsychiatry, 65(3), 1995, pp. 446-450.

[44] S. Viertiö, P. Sainio, S. Koskinen, J. Perälä, S.I. Saarni, J. Lönnqvist, and J. Suvisaari, " Mobility limitations in persons with psychotic disorder: findings from a population-based survey", Social Psychiatry and Psychiatric Epidemiology, 44, 2009, pp. 325-332.

[45] E.V. Sullivan, M.J. Rosenbloom, and A. Pfefferbaum, "Balance and Gait Deficits in Schizophrenia Compounded by the Comorbidity of Alcoholism", American Journal of Psychiatry, 161(4), 2004, pp. 751-755.

[46] A.I. Green, K. Patel, R.M. Goisman, D.B. Allison, and G Blackburn, "Weight gain from novel antipsychotic drugs: Need for action", General Hospital Psychiatry, 22(4), 2000, pp.224-235.

[47] A.E. Kazdin, "Research design in clinical psychology" $(2$ nd ed.), Needham Heights, MA: Allyn \& Bacon, 1992.
[48] J.E. Ware, and C.D. Sherbourne, "The MOS 36-item short-form health survey (SF-36): I. conceptual framework and item selection”, Medical Care, 30(6), 1992, pp. 473-483.

[49] S.L. Tunis, T.W. Croghan, D.K. Heilman, B.M. Johnstone, and R.L. Obenchain, "Reliability, validity, and application of the medical outcomes study 36- item short-form health survey (SF-36) in schizophrenic patients treated with olanzapine versus haloperidol", Medical Care, 37(7), 1999, pp.678-691.

[50] R.G. O'Brien, and M.K. Kaiser, "The MANOVA approach for analyzing repeated measures designs: An extensive primer", Psychological Bulletin, 97, 1985, pp. 316-333.

[51] T. Grant, "Physical activity and mental health - national consensus statements and guidelines for practitioners", London: Health Education Authority, 2000.

[52] Crone, "Walking back to health: A qualitative investigation into service users experiences of a walking project", Issues in Mental Health Nursing, 28(2), 2007, pp. 167-184.

[53] J. Dattilo, "Inclusive leisure services: Responding to the rights of people with disabilities" ( $2^{\text {nd }}$ ed.). State College, PA: Venture, 2002.

[54] E.L. Deci, R. Koestner, and R.M. Ryan, "A meta-analytic review of experiments examining the effects of extrinsic rewards on intrinsic motivation", Psychology Bulletin, 125, 1999, pp. 627-668.

[55] S.M. Silverstein, "Bridging the Gap between Extrinsic and Intrinsic Motivation in the Cognitive Remediation of Schizophrenia", Schizophrenia Bulletin, 36 (5), 2010, pp. 949-956.

[56] S.M. Silverstein, W.D. Spaulding, A.A. Menditto, A. Saritz, R.P. Liberman, S. Berten, and H. Starobin, "Attention shaping: a reward-based learning method to enhance skills training outcomes in schizophrenia", Schizophrenia Bulletin, 35(1), 2009, pp. 222-232.

[57] S. Glynn, and K.T. Mueser, "Social learning for chronic mental inpatients". Schizophrenia Bulletin, 12, 1986, pp. $648-668$.

[58] S. Park, C. Gibson, and T. McMichael, "Socioaffective factors modulate working memory in schizophrenia patients", Neuroscience, 139(3), 2006, pp. 373-384.

[59] P.W. Corrigan, "Use of a token economy with seriously mentally ill patients: Criticisms and misconceptions", Psychiatric Services, 46, 1995, pp. 1258-1263. 